\title{
Optimization of Western blotting analysis for the isolation and detection of membrane xenobiotic transporter ABCG2*
}

\author{
Małgorzata Szczygieł ${ }^{\bowtie}$, Marcin Markiewicz, Milena Szafraniec, Roxana Zuziak, Krystyna \\ Urbańska and Leszek Fiedor
}

Department of Biophysics, Faculty of Biochemistry, Biophysics and Biotechnology, Jagiellonian University, Kraków, Poland

\begin{abstract}
All organisms are exposed to numerous stress factors, which include harmful xenobiotics. The diversity of these compounds is enormous, thus in the course of evolution diverse biological defense mechanisms at various levels of organization have developed. One of them engages an evolutionarily conserved family of transporters from the $A B C$ superfamily, found in most species - from bacteria to humans. An important example of such a transporter is the breast cancer resistance protein (BCRP/ ABCG2), a typical integral membrane protein. It plays a key role in the absorption, distribution and elimination of a wide variety of xenobiotics, including drugs used in chemotherapy, and is involved in multidrug resistance. It also protects against phototoxic chlorophyll derivatives of dietary origin. BCRP is a hemitransporter which consists of one transmembrane domain, made of six alphahelices forming a characteristic pore structure, and one ATP-binding domain, which provides the energy from ATP hydrolysis, required for active transport of the substrates. The isolation of BCRP is still not an easy task, because its insolubility in water and the presence of membrane rafts pose serious methodological and technical challenges during the purification. The aim of this study was to optimize the methods for detection and isolation of BCRP-enriched fractions obtained from animal tissue samples. In this report we describe an optimization of isolation of a BCRP-enriched membrane fraction, which is suitable for further protein quantitative and qualitative analysis using the molecular biology tools.
\end{abstract}

Key words: Xenobiotic transporter, ABCG2, BCRP, Western blotting

Received: 05 May, 2017; revised: 22 June, 2017; accepted:

11 August, 2017; available on-line: 06 September, 2017

e-mail: gosia.szczygiel@uj.edu.pl

*A preliminary report from this work was presented in part at the XLIV Winter School of the Faculty of Biochemistry, Biophysics and Biotechnology of the Jagiellonian University "No stress - no life", February 14-18, 2017, Zakopane, Poland.

Abbreviations: $A B C, A T P$ binding cassette; $B C A$, bicinchoninic acid assay; $\mathrm{BChl}$, bacteriochlorophyll; BCRP/ABCG2, breast cancer resistance protein; Chl, chlorophyll; DAB, 3,3V-diaminobenzidine; DBA/2, pink-eye-dilution-brown-non-agouti, substrain 2 (previously 212), a mouse inbred strain; DRM, detergent resistant membranes; $\mathrm{H} \& \mathrm{E}_{\text {, }}$ hematoxylin and eosin staining; HRP, horseradish peroxidase; IHC, immunohistochemistry; S91, mouse melanoma, strain 91 (obtained by Cloudman in 1941): PAGE, polyacrylamide gel electrophoresis; PBS, phosphate-buffered saline; PBS-T, PBS containing $0.1 \%$ Tween.

\section{INTRODUCTION}

Living organisms are equipped with very well-functioning systems of stress management, which involve, among others, a superfamily of ATP binding cassette (ABC) transporters, responsible for removal of harmful metabo- lites from inside the body and protection against exogenous xenobiotics. The ABC transporters have a unique structure comprising the large multispanning transmembrane and ATP binding domains. Among such transporters, the breast cancer resistance protein (BCRP or ABCG2) is perhaps the best characterized one. Its tissue localization reflects its important role in protecting the body from toxic substances. It is found in the stem cells, the blood-brain barrier, placenta, and in the barrier tissues, which form the first line of defense, i.e. intestines, lungs, liver or kidneys (Maliepaard et al., 2001; Telbisz et al., 2007). BCRP is a $72 \mathrm{kDa}$ transmembrane protein, which consists of a single nucleotide binding domain (NBD) and a single membrane spanning domain (MSD), made of 6 transmembrane $\alpha$-helices (Ni et al., 2010). BCRP usually functions as a homodimer (Kage et al., 2002). Cholesterol and bile acids are important regulators of BCRP activity (Telbisz et al., 2013), which implies a demand for a cautious handling during its extraction from biological material and further functional analysis.

Chlorophyll metabolites, derived from plant photosynthetic pigments consumed by herbivores (including humans), are a dangerous group of xenobiotics due to their high phototoxicity (Kotkowiak et al., 2017). Their accumulation in the body may lead to lethal consequences and there must exist an efficient system of elimination of such compounds. This is performed by BCRP, the lack of which is associated with a high photosensitivity of the skin in animals fed on plant food (Jonker et al., 2002). BCRP also participates in the transport of protoporphyrin IX (Szafraniec et al., 2014) and its absence causes clinical symptoms similar to that of protoporphyria (Jonker et al., 2002; Robey et al., 2004). In an ecophysiological aspect, man and animals may also be exposed to undesirable accumulation of toxic metallochlorophyll metabolites, derived from plant food produced in soil areas contaminated with salts of heavy metals (e.g. Zn, $\mathrm{Cu}, \mathrm{Ni}$ ) (Kupper \& Kupper, 2006). Metallochlorophylls are also used as green food colorants (E140, E141), and their photocytotoxicity seems to be overlooked in the admissibility test (Watson, 2001). On the other hand, due to the aforementioned ability to photosensitize, excellent light absorption properties and biocompatibility, chlorophyllides and other polar chlorophyll and bacteriochlorophyll derivatives are investigated as photosensitizers in photodynamic therapy (Staroń et al., 2015). An example of such a photosensitizer is Zn-pheophorbide, recently shown to have a high antitumor efficacy in animal studies (Jakubowska et al., 2013) or Tookad (PdBChlide), whose strong phototherapeutic properties were confirmed in the phase III clinical trials (Azzouzi et al., 2013). 
The possibility of fast and reliable identification and characterization of xenobiotic transporters is crucial in the context of interactions between animal organisms and Chl-derived xenobiotics (Szczygieł et al., 2008), and important also from the viewpoint of multidrug resistance and its prevention in the case of chemotherapeutic agents or photosensitizers. There is a growing interest in studying BCRP in more advanced models, also using experimental animals.

There are many reports on the expression, extraction and crystallization of the BCRP protein, based on insect cells or yeast expression systems (Ozvegy et al., 2001; Scharff-Poulsen \& Pedersen, 2013), but most of them involve complex and tedious protocols. Therefore, there is still a need for a simple, robust method for BCRP isolation and detection to facilitate its quantitative and qualitative analysis. Here, we present an optimized protocol that allows for a quick detection and visualization of BCRP in the BCRP-enriched membrane fractions during their preparation from ex vivo tissue samples, suitable for further analysis via molecular biology tools.

\section{MATERIALS AND METHODS}

Animals. Sample collection for tissue analysis. The animals used in the present study were obtained from the animal breeding facility at the Mossakowski Medical Research Centre Polish Academy of Sciences, Warszawa, Poland. Male DBA/2 mice, 2-4 months old were kept in community cages, on a standard laboratory diet (LaboFeed B from Morawski, Kcynia, Poland), with free access to fresh water and a $12 \mathrm{~h}$ day/night regime. Before the experiments, the animals were quarantined and acclimatizated for two weeks. Their use for experimental purposes was approved by the 1st Local Ethics Committee for Experiments on Animals at the Jagiellonian University in Cracow (permission No. 25/2009, 13/2010 and 132/2010). After the anesthesia and sections, the tissue and organ samples were collected from the DBA/2 mice and stored in liquid nitrogen until further analyses.

Histological and immunohistochemical analyses. Freshly excised samples of tissues were immersed in a cryoprotectant (Cryomatrix ${ }^{\mathrm{TM}}$, Thermo Scientific, USA) and frozen in liquid nitrogen. The samples were cut into $4 \mu \mathrm{m}$ thick slices using a microtome (Leica CM 1100), then placed on poly-L-lysine coated microscopic glasses, fixed in cold $96 \%$ ethanol for $1 \mathrm{~min}$ and stored in phosphate-buffered saline (PBS) at $4^{\circ} \mathrm{C}$. The sections for the hematoxylin and eosin (HE) staining were prepared according to a standard protocol (Mayer, 1891). For immunohistochemical analysis, the slides were kept in PBS containing $0.1 \%$ Tween (PBS-T) for $5 \mathrm{~min}$ and a nonspecific binding was blocked by $1.5 \mathrm{~h}$ incubation in a $10 \%$ skimmed milk in PBS-T. After rinsing in PBS-T (5 min), the endogenous avidin sites were blocked by a $10 \mathrm{~min}$ incubation in egg white solution. After rinsing with distilled water ( $3 \mathrm{~min})$, the endogenous peroxidase activity was blocked by immersing in $3 \% \mathrm{H}_{2} \mathrm{O}_{2}$ for $15 \mathrm{~min}$. Then the slides were incubated with the BXP-53 antibody (Sigma-Aldrich, Germany) at a 1:100 dilution for $1 \mathrm{~h}$ at $30^{\circ} \mathrm{C}$ (the intestines) or $2 \mathrm{~h}$ at room temperature (the kidneys and the liver). Next, the slides were incubated for $1.5 \mathrm{~h}$ at room temperature with a biotinylated secondary antibody (biotin mouse anti-rat IgG 1/2a, BD Pharmingen) at a 1:200 dilution. The slides were rinsed three times with PBS-T, and incubated with streptavidinhorseradish peroxidase (HRP) for further $30 \mathrm{~min}$. After the formation of the avidin-biotin-peroxidase complex the slides were rinsed three times with PBS-T, and treated with 3,3V-diaminobenzidene (DAB, Vector Laboratories, Burlingame, USA) to detect the bound peroxidase. The reaction was terminated by rinsing the slides in cold tap water. After counterstaining with hematoxylin and $0.1 \%$ ammonia water, the cover slips were mounted using a water-based adhesive. The negative controls were prepared by omission of the primary and secondary antibodies.

Image analysis of tissue slices. The slides were examined under a light microscope (Nikon Eclipse TS100) using a $100 \times$ magnification. The images were taken using a Nikon D7000 camera and a Camera Control Pro 2 software (Nikon Instruments, Badhoevedorp, Netherlands). Image analysis was performed using a freeware ImageJ v1.46r (Center for Information Technology National Institutes of Health, Maryland, USA, https://imagej.nih.gov/ij/).

Protein isolation, quantification and detection. The key steps of protein isolation and Western blotting detection procedures were verified in a sequence shown in Fig. 1.

Several different variants of the isolation procedure were tested until satisfactory results were obtained, based on the previously described methods in which some preparative steps were modified (Théou et al., 2005; Xu et al., 2007). Briefly, the protocol involved the following steps: (i) tissue fragmentation and homogenization of the samples, (ii) lysis with various buffers and detergents, centrifugation to remove insoluble fractions, (iii) determination of protein concentration, (iv) gel loading, and (v) BCRP detection.

These points are described below, along with an indication of the different test variants. At the end of this section, there is a comprehensive description of the optimized procedure.

(i) Tissue fragmentation. The samples were excised and fragmented using a scalpel. For isolation, 10-100 mg tissue portions were taken. After the addition of lysis buffer, the samples were homogenized using either a hand-held mechanical homogenizer, a glass homogenizer or a mortar, or homogenized with the use of metal beads. An additional step of sonication was also performed.

(ii) Detergents and lysis buffers. A range of lysis buffers containing various mild detergents was tested to find the most suitable one. Initially, based on the literature, the following buffers were used: a $20 \mathrm{mM}$ Tris buffer ( $\mathrm{pH}$ 7.4), containing $150 \mathrm{mM} \mathrm{NaCl}, 1 \mathrm{mM}$ sodium orthovanadate, $10 \mathrm{mM} \mathrm{NaF}, 1 \mathrm{mM}$ PMSF, $0.5 \mu \mathrm{g} / \mathrm{ml}$ leupeptin, $1 \mu \mathrm{g} / \mathrm{ml}$ pepstatin, $10 \mathrm{KIU} / \mathrm{ml}$ aprotinin, and $1 \%$ Triton X-100 (Xu et al., 2007), and a $25 \mathrm{mM}$ Tris buffer (pH 7.4) containing $150 \mathrm{mM} \mathrm{NaCl}, 1 \mathrm{mM}$ EDTA, $2 \mathrm{mM}$ phenylmethylsulfonyl fluoride, and 1\% Triton X-100 (Théou et al., 2005). Afterwards, a TNN buffer containing $50 \mathrm{mM}$ Tris ( $\mathrm{pH} 7.5$ ), $150 \mathrm{mM} \mathrm{NaCl}, 0.5 \%$ NP-40, $0.2 \mathrm{mM}$ sodium orthovanadate, $1 \mathrm{mM}$ PMSF and protease inhibitors without EDTA was used, in combination with several detergents, including Tween-20 and Brij 58. Finally, a two-step lysis was implemented using two buffers in order to separate the soluble protein fraction from the detergent resistant membrane (DRM) fraction, i.e. buffer 1, containing $50 \mathrm{mM}$ Tris- $\mathrm{HCl}(\mathrm{pH}$ 7.5), $150 \mathrm{mM} \mathrm{NaCl}, 1 \%$ Brij 58, $1 \mathrm{mM}$ sodium orthovanadate, $1 \mathrm{mM}$ PMSF and protease inhibitors without EDTA, and its modification, buffer 2 (lysis buffer for membrane rafts), additionally containing $0.5 \%$ SDS and $1 \% \beta$-mercaptoethanol. 


\section{MEMBRANE \\ PROTEIN \\ EXTRACTION \\ WORKFOW}

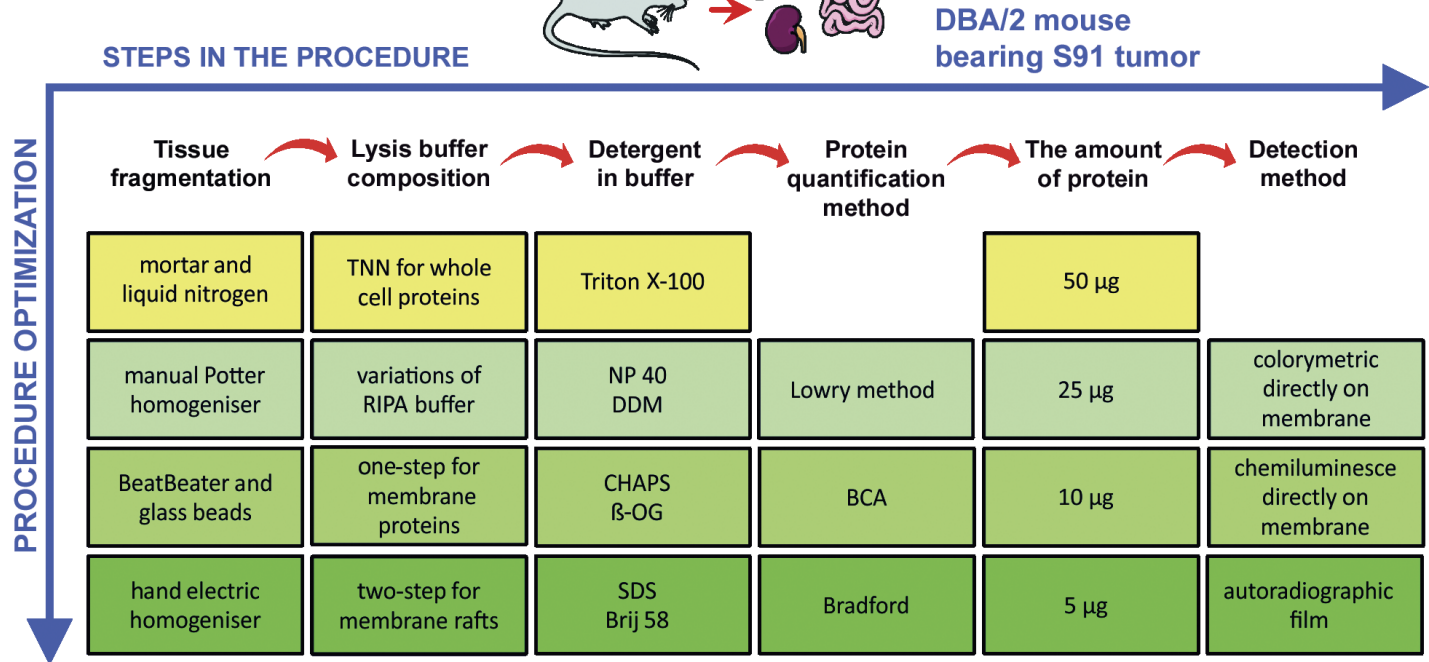

Figure 1. A diagram showing the optimization steps in isolation of BCRP and its detection by Western blotting technique.

(iii) Protein quantification. The total protein concentration was initially determined using either the Lowry assay or the BCA assay, but because of the interference with detergents, in particular with SDS, present in lysis buffers, it was changed to the Bradford assay (Bradford, 1976) as the method of choice.

(iv) Optimization of gel loading. Initially, aliquots of $50 \mu \mathrm{g}$ of total protein were loaded per well onto polyacrylamide gels. During the protocol optimization this amount was lowered gradually down to $5 \mu \mathrm{g}$ of protein per well, which was sufficient for the accurate detection by Western blotting.

(v) Detection method. For protein detection, two different HRP-conjugated substrates were tested. First, the colorimetric Opti-4CN ${ }^{\mathrm{TM}}$ Substrate Kit (BioRad, USA) was used; the membranes were incubated for $30 \mathrm{~min}$ in the Opti4CN ${ }^{\mathrm{TM}}$ Substrate and washed in deionized $\mathrm{H}_{2} \mathrm{O}$ for $15 \mathrm{~min}$. The visualized membranes were dried and photographically documented. Because of the low sensitivity of the colorimetric assay, a chemiluminescent detection was employed as follows: the membranes were incubated with the LumiGLO Peroxidase Chemiluminescent Reagent (Cell Signaling Technology, USA) for $1 \mathrm{~min}$ and visualized either by using a ChemiDoc $^{\mathrm{TM}}$ Imaging System (BioRad, USA) or on a film in a darkroom ( 2 min exposure time). The images of the blots were processed using the ImageJ software.

Coomassie Blue staining. A standard SDS/PAGE was performed using a $20 \mu \mathrm{g}$ load of protein per well. After the separation, the gels were rinsed in a Coomassie Blue solution $(0.1 \%$ Coomassie Brilliant Blue R-250, $40 \%$ methanol and $10 \%$ acetic acid in distilled water) for $45 \mathrm{~min}$ at room temperature and washed with a destaining solution $(20 \%$ methanol and $10 \%$ acetic acid in distilled water) for $1 \mathrm{~h}$. The destaining solution was exchanged every $10 \mathrm{~min}$. The gels were photographed and stored in distilled water at $4^{\circ} \mathrm{C}$.

Optimized two-step isolation procedure. The tissue samples were dissected using a scalpel, suspended in 500 $\mu \mathrm{l}$ of ice-cold lysis buffer 1 and homogenized using a TH-02 tissue homogenizer (OMNI International, USA). The homogenates were centrifuged at $16000 \times g$ for 25 min at $4^{\circ} \mathrm{C}$. The supernatants containing soluble proteins were collected and transferred to fresh Eppendorf tubes. The pellets were suspended in $400 \mu \mathrm{l}$ of ice-cold lysis buffer 2 , sonicated on ice 5 times for $15 \mathrm{~s}$ and centrifuged at $16000 \times \mathrm{g}$ for $10 \mathrm{~min}$ at $4^{\circ} \mathrm{C}$. The supernatants were collected and stored at $-20^{\circ} \mathrm{C}$ until further use. The total protein concentration in the DRM fraction was determined using the Bradford assay.

Western blotting. Aliquots of $5 \mu \mathrm{g}$ of DRM fraction obtained from tissue lysates were separated by SDSPAGE on a $10 \%$ polyacrylamide gel and transferred onto nitrocellulose membrane with the use of standard wet-tank electrotransfer technique $(60 \mathrm{~V}, 90 \mathrm{~min})$. The membranes containing separated proteins were blocked in a 5\% skimmed milk solution in a Tris-buffered saline containing $0.5 \%$ Tween 20 (TBS-T) and incubated overnight at $4^{\circ} \mathrm{C}$ with the primary BXP-53 rat antibodies against BCRP at 1:200 dilution; the mouse monoclonal anti- $\beta$-actin antibodies (Sigma Aldrich, Germany) at 1:2000 dilution were used as a reference to maintain equal protein loads. The membranes were washed $3 \times 10$ $\mathrm{min}$ in TBS-T, incubated for $90 \mathrm{~min}$ with the secondary HRP-conjugated antibodies (polyclonal rabbit antirat against primary ABCG2 antibodies at 1:2500 dilution and polyclonal goat antimouse against primary $\beta$-actin antibodies at 1:1000 dilution; Dako, Denmark), and washed again $3 \times 10 \mathrm{~min}$ in TBST. All steps were conducted at room temperature. After 1 min incubation at room temperature with LumiGLO Peroxidase Chemiluminescent Reagent, the blots were visualized on a film in a darkroom (2 min exposure). A semi-quantitative densitometric analysis of the immunoblots was performed using the ImageJ software.

\section{RESULTS AND DISCUSSION}

Membrane proteins are naturally associated with lipid bilayers, and often they are embedded into the membrane rafts. Their analysis is difficult because of high hydrophobicity and poor solubility in aqueous solutions. The use of detergents, which is crucial in their solubilization, poses difficulties in their extraction, purification and structural analyses (Mancia \& Love, 2010). Membrane proteins are divided into several classes, which are 
characterized by various types of association with the membrane; these include transmembrane proteins, immersed into the lipid bilayer, as well as proteins covalently and noncovalently attached to the membrane. The different types of interactions, along with some individual characteristics of those proteins (such as stability or $\mathrm{pH}$ dependency) make their isolation particularly intricate (Kubicek et al., 2014).

BCRP is an example of a membrane protein with a large multispanning domain, residing in detergent insoluble membrane rafts (Hegedus et al., 2015; Storch et al., 2007), and therefore it is not easily accessible.

\section{BCRP localization}

The immunohistochemical analysis shows the presence of BCRP protein in renal, hepatic, small intestine and large intestine cells from DBA / 2 mice while it was not detected in heart or spleen (Fig. 2). In the kidney, BCRP is localized in epithelial cells of nephron tubules, in the liver it is present in hepatocytes, and in the small and large intestine in epithelial cells of the intestinal villi. The analysis based on the use of monoclonal and polyclonal antibodies shows the membrane localization of BCRP (Diestra et al., 2002; Doyle \& Ross, 2003). These tissue and cellular localizations of BCRP correlate with the functions of the transporter (Maliepaard et al., 2001; Fetsch et al., 2006). The transporter is mainly detected in cells from organs of secretive functions, such as hepatocytes, small intestinal epithelial cells, colon, kidneys and lungs, and in the blood brain barrier and placenta (Gutmann et al., 2005; Takano et al., 2006).

The immunohistochemical staining allows for the visualization of protein expression directly in the tissue, because the structure of the organ in the slice remains intact during its preservation. IHC is a relatively simple but time-consuming method of analysis. It requires some experience and although it provides a valuable information about the expression of the protein of choice, it is not considered to be quantitative, especially for large numbers of samples.

In order to detect BCRP in a more quantitative way, the Western blotting analysis was done. Various modifications in both protein isolation and the detection methods were applied as described under Materials and Methods, with the aim to achieve the highest yield of the DRM fraction and the most sensitive protein visualization using this technique. The experiments were carried out ex vivo on samples of the DBA/ 2 mouse tissues and the entire membrane protein extraction and detection workflow involves several steps, which all underwent optimization (Fig. 1).

\section{Tissue fragmentation}

During the initial step of mechanical tissue homogenization, multiple cycles of freezing and thawing should be avoided in order to prevent protein degradation and aggregation, which additionally may lead to errors in determining its concentration. Therefore, the mechanical treatment of samples should be selected carefully to obtain sufficient protein yields (Gorr \& Vogel, 2015). Several approaches were tested, taking in the consideration the yield of protein and shortening the time of the whole procedure to minimize the chances for generating artifacts. At first, frozen tissue samples were ground in a mortar in liquid nitrogen. Unfortunately, with a large number of samples to process, it turned out to be an overwhelmingly long step, and the amounts of isolated protein were not satisfactory. Similar difficulties were

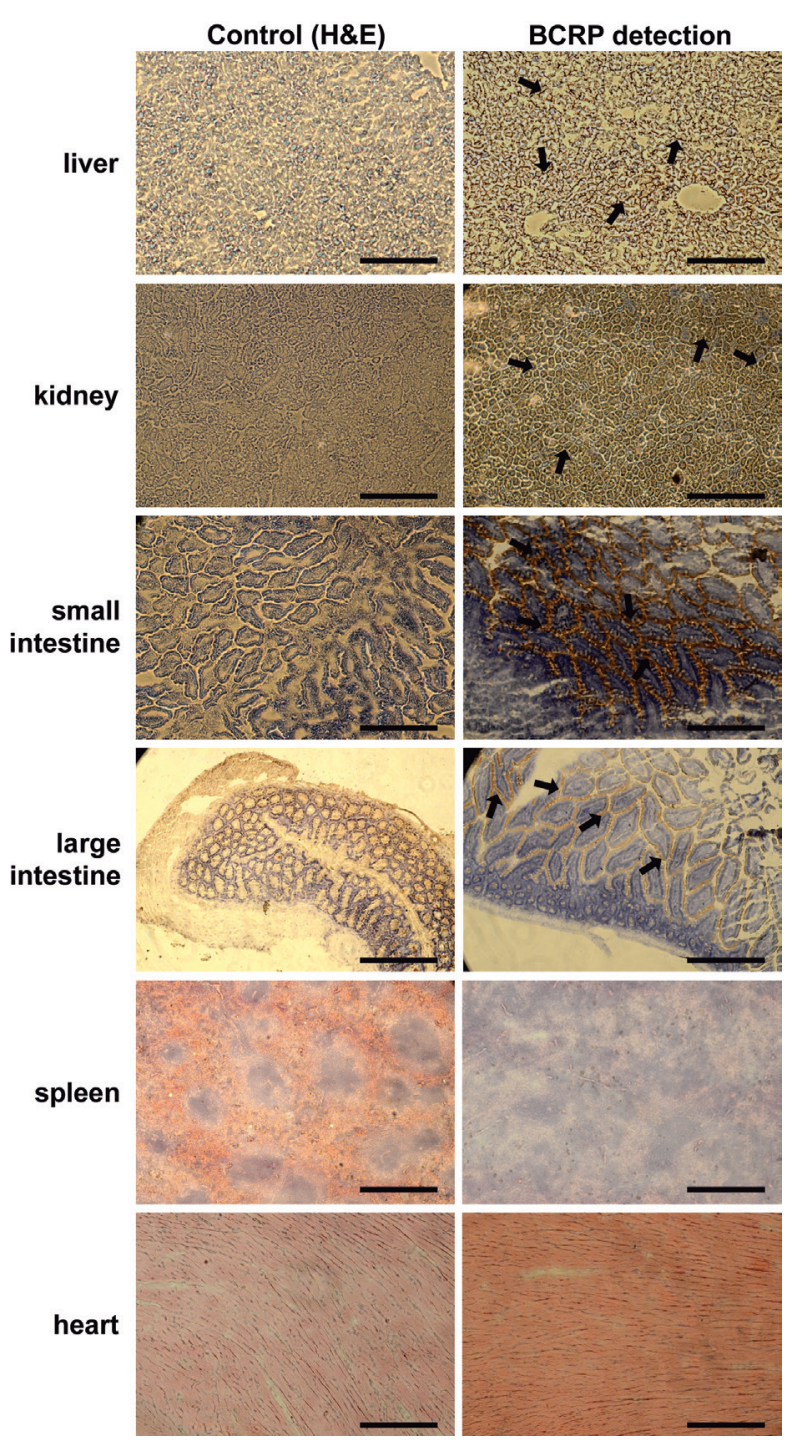

Figure 2. The immunohistochemical staining of various tissues from the $D B A / 2$ mice.

BCRP (ABCG2) was detected in frozen tissue sections using the BXP-53 monoclonal antibody, stained with the anti-mouse HRP$\mathrm{DAB}$ antibody (brown color indicates the presence of BCRP) and counterstained with hematoxylin (blue background). Controls were processed without the primary antibody. Scale bar: $5 \mu \mathrm{m}$.

met when using a manual Potter homogenizer. It usually gives low protein yields, while prolonged isolation time increases the number of freeze-thaw cycles, increasing the risk of denaturation (Mitchell et al., 2005). Mechanical devices are more efficient, but they may also lead to protein denaturation due to the heating or oxidation due to the contact with air. In this respect, a short homogenization with the use of a handheld electrical homogenizer followed by an additional sonication proved to be the most effective.

\section{The choice of detergent and lysis buffer}

Several lysis buffers dedicated to membrane proteins were investigated. BCRP is susceptible to proteolytic degradation and thus a rich set of protease inhibitors must be applied during the isolation. It is known that detergent-based extraction gives the highest membrane protein yields among other considered methods (Lehner et al., 2003). Initially, a single-step isolation procedure was used, varying only the detergent. The isolation with the use of a 
TNN buffer gave insufficient protein yields (not shown). Therefore, other lysis buffers were tried and the results compared on a single blot, including a TNN buffer, two buffers from previously published protocols (Théou et al., 2005; Xu et al., 2007), and a self-developed one-step membrane lysis buffer, in all cases using the same colorimetric detection method. However, none of the tested buffers proved effective, while the colorimetric assay turned out to be insufficiently specific and not very sensitive. The one-step membrane lysis buffer was also tried in combination with chemiluminescence detection done directly on the membrane. However, neither the detection method was specific enough nor the isolation itself yielded samples of satisfactorily high protein concentrations (not shown).

The following mild detergents were not effective in the extraction of BCRP from the membranes: Brij58, Triton X100 and NP40. Therefore, an introduction of a second extraction step was necessary, with the use of a stronger detergent, SDS, which yielded sufficient protein amounts. As the next optimization stage, a two-step method was employed in order to specifically obtain the DRM protein fraction.

The results obtained using the one- and two-step isolation protocols are shown in Fig. 3B. In comparison to one-step isolation, the protein bands from two-step pro- tocol were visible and of a good quality. Both fractions from the twostep protocol were checked for the BCRP content. The fraction obtained in the second step of the procedure contained more protein and produced lower background, as compared to the first one, suggesting a higher purity of the protein.

The lysates obtained with the use of the optimized two-step isolation yielded total protein concentrations in the range of $1-10 \mathrm{mg} / \mathrm{ml}$. The efficiency of the isolation procedure amounts to approximately $0.2 \mathrm{mg}$ of protein per $1 \mathrm{mg}$ of the tissue, with the DRM fraction being a quarter of that. The densitometric analysis shows that the protein fraction obtained by the two-step protocol is about five-fold enriched (Fig. 3C) in comparison to the most effective one-step protocol.

Another advantage of using a two-step lysis method is the partitioning of the proteins; the majority of cytoplasmic proteins remain in the supernatant collected in the first step. The densitometric analysis confirms that most of BCRP is accumulated in the membrane fraction and the enrichment factor reaches 15 (Fig. 3C).

To obtain the active transporter using SDS, which disintegrates the nuclear membrane, DNAse must be used to prevent unwinding of DNA, which may interfere with the analysis of protein concentration and with the trans-
A

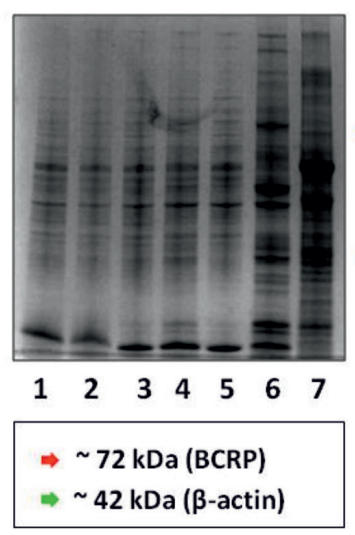

D

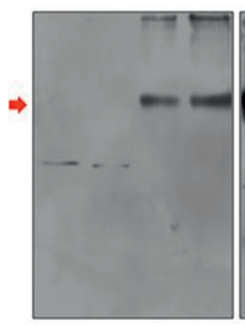

$\begin{array}{llllllll}1 & 2 & 3 & 4 & 1 & 2 & 3 & 4\end{array}$
B
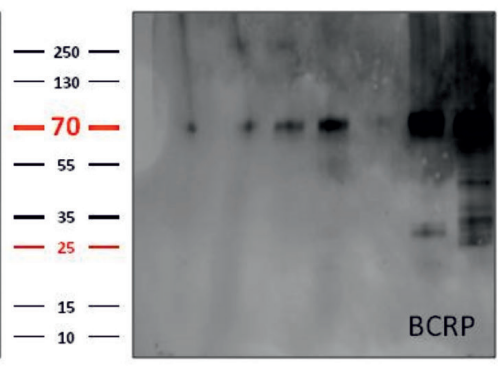

$\begin{array}{lllllll}1 & 2 & 3 & 4 & 5 & 6 & 7\end{array}$
C

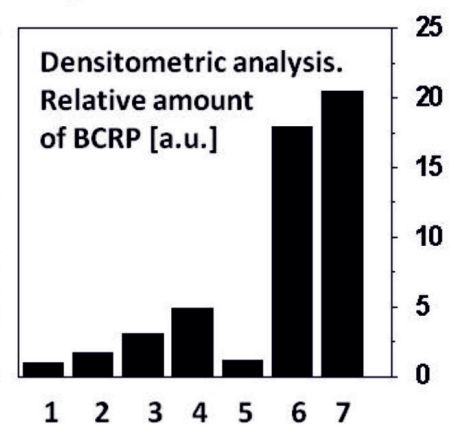

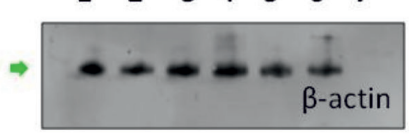

$\mathbf{E}$

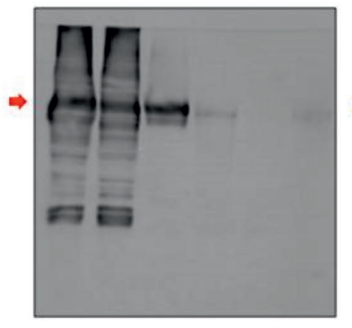

$\begin{array}{llllll}1 & 2 & 3 & 4 & 5 & 6\end{array}$

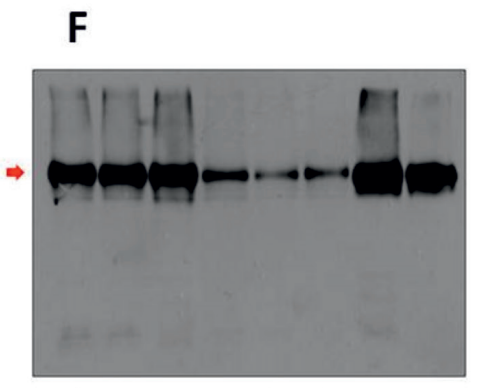

$\begin{array}{llllllll}1 & 2 & 3 & 4 & 5 & 6 & 7 & 8\end{array}$

Figure 3. The representative results of Western blotting and Coomassie staining (details in the text).

The lysates were prepared from tissues obtained from in vivo DBA/2 mice. A, B, C: comparison of Coomassie staining (A) and Western blotting (B, C) analysis as an evaluation of different protein isolation protocols based on the kidney lysates. Each sample contained either $5 \mu \mathrm{g}$ of total protein (Western blotting) or $20 \mu \mathrm{g}$ of protein (Coomassie staining). Lane and bar designation: 1 - according to (Xu et al., 2007), 2 - according to (Théou et al., 2005), 3 - samples lysed in the TNN buffer, 4 - one step membrane lysis buffer, 5 - two step lysis buffer for membrane rafts, supernatant No. 1 (cytoplasmic fraction), 6 - two step lysis buffer for membrane rafts, supernatant No. 2 (membrane fraction), 7 - BCRP overexpressed in yeast membranes (positive control). The gel after separation was stained with Coomasie blue (A) or transferred to a nitrocellulose membrane and BCRP was analyzed using Western blotting (B, top); $\beta$-actin was used as a loading control (B, bottom). C: the relative amount of BCRP determined by densitometric analysis of the signals obtained from the membrane in B; normalized to the $\beta$-actin level. D, E, F: two step lysis buffer for membrane rafts, DRM protein fraction, $5 \mu \mathrm{g}$ protein per lane; detection on film. D: two different primary antibodies against different BCRP epitopes; Ab 63907 - on the left; BXP-53 - on the right. Lane designation: 1-2: liver; 3-4: kidneys. E: evaluation of specificity of the BXP-53 antibody. Lane designation 1-2: kidneys (often serve as positive control for BCRP); lane 3: liver; lanes 4-6 (negative control): spleen, muscles, heart F: Blot obtained with the use of the optimized protocol. Lane designation: 1-3: small intestine, 4-6: large intestine, 7-8: liver. 
fer of the samples into the gel. Also to obtain a blotting band of pure BCRP, unbound to lipids, special denaturing conditions in sample buffer have to be applied at $60^{\circ} \mathrm{C}$, what counteracts protein aggregation.

\section{Protein quantification and optimization of gel loading}

For the determination of the total protein concentration in the fractions obtained, the Lowry, BCA and Bradford assays have been compared. The former two assays were found unreliable due to the interference with detergents and disulfide reducing agents, and also the lipid rafts present in the samples were lowering their accuracy. In effect, the Bradford assay was found the most suitable.

In order to maintain equal protein loads across the gels, a loading control in the form of a housekeeping gene is usually needed (Gorr \& Vogel, 2015). In the present case, $\beta$-actin seems to be adequate as a positive control. In addition, the optimization of protein amount is necessary to obtain sharp enough bands suitable for further densitometric analyses of the blots (Taylor \& Posch, 2014). The recommended aliquots of protein loaded onto a gel are usually in the range of $25-50 \mu \mathrm{g}$, which often is unjustified and excessive (Mahmood \& Yang, 2012). Indeed, the tests have shown that the amount of $5 \mu \mathrm{g}$ of protein is optimal to obtain clear and distinct bands while avoiding gel overloading.

\section{Detection method}

Two types of antibodies against BCRP were tested for its detection. The BXP-53 antibody, targeting the BCRP epitope localized between the amino acid residues 221 and 394, gives a much stronger signal than the Ab63907 antibody, which recognizes the region between the residues 550 and 650 . This observation suggests that the intracellular region of the transporter recognized by the former antibody is better accessible than the extracellular moiety (Fig. 3D). In addition, when using the BXP-53 antibody, in all samples from kidneys, along with the BCRP band $(\sim 72 \mathrm{kDa})$, an extra band of molecular mass of approximately $35 \mathrm{kDa}$ was detected (Fig. 3D), similar to the one reported earlier (Eldashera et al., 2013; Mao et al., 2004). It was not seen when the Ab63907 antibody was used, suggesting that the $35 \mathrm{kDa}$ peptide might be a specific degradation product of BCRP lacking the epitope recognized by this antibody.

Concerning the signal visualization method, the HRPbased chemiluminescent detection paired with exposure of the membrane to a autoradiographic film is by far the most sensitive among tested methods; already $1 \mu \mathrm{g}$ of protein is enough to obtain a clearly resolved band (Bass et al., 2017).

To confirm the specificity of our detection method, a negative control, i.e. samples of tissues in which BCRP is not expressed, was run on a gel in parallel to samples of tissues with high expression of BCRP (Fig. 3E). Sharp BCRP bands were obtained in the case of kidneys and liver, while no signal was detected in the heart, muscles or spleen. A negative control Western blotting analysis with only the secondary antibodies was also done on samples from various tissues in order to confirm the specificity of the used antibodies and no nonspecific biding was observed (not shown).

\section{Coomassie staining}

SDS/PAGE followed by a Coomassie Brilliant Blue staining was run in order to determine the purity of isolated protein mixtures. In the case of liver and kidney, there is a clear difference between the lysates originating from the 2nd protein fraction obtained with the use of the two-step optimized isolation protocol and the other methods used (Fig. 3A). Obviously, the protein patterns differ across organs, which is understandable considering the expression profiles of distant tissues. However, they are highly similar between the same organs in lysates obtained with the use of all evaluated protocols except for the optimized two-step method. Moreover, in the latter samples there is a lower number of distinct protein bands. They are also sharper and of higher density compared to the other lysates, suggesting a better overall protein purity (Fig. 3A). These results may indicate that TNN, one-step and other similar protocols $(\mathrm{Xu}$ et al., 2007; Théou et al., 2005) yield a mixture of the soluble and membrane proteins, while the present method of choice seems more efficient in separating the protein fractions.

\section{Optimized two-step procedure}

A two-step method was employed in order to obtain the DRM protein fraction, followed by binding of a HRP-conjugated secondary antibody and exposure of an autoradiographic film. The method gave much higher membrane protein yields, which at first lead to the overloading of the detection system, improved after applying lower amounts of the protein. The sensitivity of the autoradiographic detection method turned out to be high enough to visualize protein samples as low as $1-5 \mu \mathrm{g}$.

Figure $3 \mathrm{~F}$ depicts a representative Western blot image obtained with the use of the optimized protocol, using the two-step isolation method, i.e. two separate lysis buffers and mechanical sample homogenization followed by s sonication, and transfer onto a nitrocellulose membrane via a wet-tank technique. The gel was visualized with the use of a HRP substrate on an autoradiographic film. This procedure ensures consistent and reproducible results between experiments.

In order to evaluate the usefulness of the optimized protocol in other experimental systems, BCRP isolation and detection in tissues originating from other mouse strains (C57Bl and SCID) and other species (hamster) were performed (not shown). The obtained results confirm that it is a versatile procedure, applicable to tissues of different origin and in a variety of experimental models.

\section{CONCLUSIONS}

The Western blotting technique is a very useful tool in molecular biology research; however, it requires a thorough understanding of each stage of the procedure. It also requires that the methodology used is adapted to each individual experimental model, so that the results are interpretable and reliable. The mechanical protein isolation from the tissue must be carefully selected and, on the other hand, not to cause protein degradation. The key aspect is the choice of a buffer with the appropriate detergent, especially in the case of proteins embedded in the membrane rafts. The method of estimating the amount of protein is also very important. Antibodies must be validated using both positive and negative controls to ensure their specificity. The detection method should be sensitive and adequate to protein concentration.

Membrane proteins, including ABCG2, have proven to be very difficult to study due to their relatively hydrophobic properties and the lack of stability in aqueous solutions. We have applied a step-by-step protocol for the isolation and detection of BCRP, which provides consistent and reproducible results. The methodology described in this paper improves the BCRP extraction from tissue samples and allows for further quantitative 
and qualitative analysis of the protein by molecular biology tools.

\section{Conflicts of interests}

The authors declare no competing interests.

\section{Acknowledgements}

This work was supported in part by the National Science Centre of Poland (grant No. 0505/B/P01/2011/40 to K.U.) and by the Foundation for Polish Science (grant No. TEAM/2010-5/3 to L.F.). The Faculty of Biochemistry, Biophysics and Biotechnology of the Jagiellonian University is partner of the Leading National Research Center (KNOW) supported by the Ministry of Science and Higher Education of Poland.

\section{REFERENCES}

Azzouzi AR, Barret E, Moore CM, Villers A, Allen C, Scherz A, Emberton M (2013) TOOKAD: Soluble vascular-targeted photodynamic (VTP) therapy: Determination of optimal treatment conditions and assessment of effects in patients with localised prostate cancer. BJU Int 112: 766-774. doi: 10.1111/bju.12265

Bass JJ, Wilkinson DJ, Rankin D, Phillips BE, Szewczyk NJ, Smith K, Atherton PJ (2017) An overview of technical considerations for Western blotting applications to physiological research. Scand J Med Sci Sports 27: 4-25. doi: 10.1111/sms.12702

Bradford M (1976) A rapid and sensitive method for the quantification of microgram quantities of protein utilizing the principle of protein- dye binding. Anal Biochem 72: 248-254. doi: 10.1016/0003$2697(76) 90527-3$

Diestra JE, Scheffer GL, Català I, Maliepaard M, Schellens JHM, Scheper RJ, Izquierdo MA (2002) Frequent expression of the multidrug resistance-associated protein BCRP/MXR/ABCP/ABCG2 in human tumours detected by the BXP-21 monoclonal antibody in paraffin-embedded material. J Pathol 198: 213-219. doi: 10.1002/ path.1203

Doyle LA, Ross DD (2003) Multidrug resistance mediated by the breast cancer resistance protein BCRP (ABCG2) Oncogene 22: 73407358. doi: 10.1038/sj.onc. 1206938

Eldashera LM, Wena X, Littlea MS, Bircsaka KM, Yacovinoa LL, Aleksunesa LM (2013) Hepatic and renal Bcrp transporter expression in mice treated with perfluorooctanoic acid. Toxicol Appl Pharmacol 306: 108-113. doi: 10.1016/j.tox.2013.02.009

Fetsch PA, Abati A, Litman T, Morisaki K, Honjo Y, Mittal K, Bates SE (2006) Localization of the ABCG2 mitoxantrone resistanceassociated protein in normal tissues. Cancer Lett 235: 84-92. doi: 10.1016/j.canlet.2005.04.024

Gorr TA, Vogel J (2015) Western blotting revisited: Critical perusal of underappreciated technical issues. Proteomics - Clin Appl 9: 396-405. doi: $10.1002 /$ prca.201400118

Gutmann H, Hruz P, Zimmermann C, Beglinger C, Drewe J (2005) Distribution of breast cancer resistance protein (BCRP/ABCG2) mRNA expression along the human GI tract. Biochem Pharmacol 70: 695-699. doi: 10.1016/j.bcp.2005.05.031

Hegedus C, Telbisz A, Hegedus T, Sarkadi B, Ozvegy-Laczka C (2015) Lipid regulation of the ABCB1 and ABCG2 multidrug transporters. Adv Cancer Res 125: 97-137. doi: 10.1016/bs.acr.2014.10.004

Jakubowska M, Szczygieł M, Michalczyk-Wetula D, Susz A, Stochel G, Elas M, Urbanska K (2013) Zinc-pheophorbide a-highly efficient low-cost photosensitizer against human adenocarcinoma in cellular and animal models. Photodiagnosis Photodyn Ther 10: 266-277. doi: 10.1016/j.pdpdt.2012.12.004

Jonker JW, Buitelaar M, Wagenaar E, Valk MA. van der Scheffer GL, Scheper RJ, Schinkel AH (2002) The breast cancer resistance protein protects against a major chlorophyll-derived dietary phototoxin and protoporphyria. Proc Natl Acad Sci USA 99: 15649-15654. doi: 10.1073/pnas.202607599

Kage K, Tsukahara S, Sugiyama T, Asada S, Ishikawa E, Tsuruo T, Sugimoto Y (2002) Dominant-negative inhibition of breast cancer resistance protein as drug efflux pump through the inhibition of S-S dependent homodimerization. Int J Cancer 97: 626-630. doi: 10.1002/ijc.10100

Kotkowiak M, Dudkowiak A, Fiedor L (2017) Intrinsic photoprotective mechanisms in chlorophylls. Angew Chemie Int Ed 56: 10457-10461. doi: 10.1002/anie.201705357

Kubicek J, Block H, Maertens B, Spriestersbach A, Labahn J (2014) Expression and purification of membrane proteins. Methods Enzymol 541: 117-140. doi: 10.1016/B978-0-12-420119-4.00010-0
Kupper H, Kupper CF (2006) [Heavy metal]-chlorophylls formed in vivo during heavy metal stress and degradation products formed during digestion extraction and storage of plant material. In Chlorophylls and Bacteriochlorophylls 25: 67-77

Lehner I, Niehof M, Borlak J (2003) An optimized method for the isolation and identification of membrane proteins. Electrophoresis 24: 1795-1808. doi: 10.1002/elps.200305387

Mahmood T, Yang PC (2012) Western blot: Technique theory and trouble shooting. N Am J Med Sci 4 429-434. doi: 10.4103/19472714.100998

Maliepaard M, Scheffer GL, Faneyte IF, Gastelen MA, van Pijnenborg ACLM, Schinkel AH, Schellens JHM (2001) Subcellular localization and distribution of the breast cancer resistance protein transporter in normal human tissues. Cancer Res 61: 3458-3464.

Mancia F, Love J (2010) High-throughput expression and purification of membrane proteins. J Struct Biol 172: 85-93. doi: 10.1016/j. jsb.2010.03.021

Mao Q, Conseil G, Gupta A, Cole SPC, Unadkat JD (2004) Functional expression of the human breast cancer resistance protein in Pichia pastoris. Biochem Biophys Res Commun 320: 730-737. doi: 10.1016/j. bbrc.2004.06.012

Mayer P (1891) Uber das Farben mit Hamatoxylin. Mitt Zool Stat Neapel.

Mitchell BL, Yasui Y, Li CI, Fitzpatrick AL, Lampe PD (2005) Impact of freeze-thaw cycles and storage time on plasma samples used in mass spectrometry based biomarker discovery projects. Cancer Inform 1: 98-104

Ni Z, Bikadi Z, Rosenberg MF, Mao Q (2010) Structure and function of the human breast cancer resistance protein (BCRP/ABCG2) Curr Drug Metabol 11: 603-617. doi: 10.2174/138920010792927325

Ozvegy C, Litman T, Szakács G, Nagy Z, Bates S, Váradi A, Sarkadi B (2001) Functional characterization of the human multidrug transporter ABCG2 expressed in insect cells. Biochem Biophys Res Commun 285: 111-117. doi: 10.1006/bbrc.2001.5130

Robey RW, Steadman K, Polgar O, Morisaki K, Blayney M, Mistry P, Bates SE (2004) Pheophorbide a is a specific probe for ABCG2 function and inhibition. Cancer Res 64: 1242-1246. doi: 10.1158/0008-5472.CAN-03-3298

Scharff-Poulsen P, Pedersen PA (2013) Saccharomyces cerevisiae-based platform for rapid production and evaluation of eukaryotic nutrient transporters and transceptors for biochemical studies and crystallography. PLoS One 8. doi: 10.1371/journal.pone.0076851

Staroń J, Boroń B, Karcz D, Szczygieł M, Fiedor L (2015) Recent Progress in chemical modifications of chlorophylls and bacteriochlorophylls for the applications in photodynamic therapy. Curr Med Chem 22: 3054-3074. doi: 10.2174/092986732266615081 8104034

Storch CH, Ehehalt R, Haefeli WE, Weiss J (2007) Localization of the human breast cancer resistance protein (BCRP/ABCG2) in lipid rafts/caveolae and modulation of its activity by cholesterol in vitro. Pharmacology 323: 257-264. doi: 10.1124/jpet.107.122994

Szafraniec MJ, Szczygieł M, Urbanska K, Fiedor L (2014) Determinants of the activity and substrate recognition of breast cancer resistance protein (ABCG2) Drug Metab Rev 46: 459-474. doi: 10.3109/03602532.2014.942037

Szczygieł M, Urbańska K, Jurecka P, Stawoska I, Stochel G, Fiedor L (2008) Central metal determines pharmacokinetics of chlorophyllderived xenobiotics. J Med Chem 51: 4412-4418. doi: 10.1021/ jim7016368

Takano M, Yumoto R, Murakami T (2006) Expression and function of efflux drug transporters in the intestine. Pharmacol Ther 109: 137161. doi: 10.1016/j.pharmthera.2005.06.005

Tavlor SC, Posch A (2014) The design of a quantitative western blot experiment. Biomed Res Int 2014. doi: 10.1155/2014/361590

Telbisz A, Müller M, Özvegy-Laczka C, Homolya L, Szente L, Váradi A, Sarkadi B (2007) Membrane cholesterol selectively modulates the activity of the human ABCG2 multidrug transporter. Biochim Biophys Acta 1768: 2698-2713. doi: 10.1016/j.bbamem.2007.06.026

Telbisz A, Ozvegy-Laczka C, Heged T, Aradi A, Sarkadi B (2013) Effects of the lipid environment cholesterol and bile acids on the function of the purified and reconstituted human ABCG2 protein. Biochem J 450: 387-395. doi: 10.1042/BJ20121485

Théou N, Gil S, Devocelle A, Julié C, Lavergne-Slove A, Beauchet A, Emile JF (2005) Multidrug resistance proteins in gastrointestinal stromal tumors: Site-dependent expression and initial response to imatinib. Clin Cancer Res 11: 7593-7598. doi: 10.1158/1078-0432. CCR-05-0710

Watson DH (2001) Food chemical safety. CRC Press.

Xu J, Peng H, Chen Q, Liu Y, Dong Z, Zhang J-T (2007) Oligomerization domain of the multidrug resistance-associated transporter ABCG2 and its dominant inhibitory activity. Cancer Res 67: 4373-4381. doi: 10.1158/0008-5472.CAN-06-3169 